\title{
Los placeres del exceso: Estéticas de lo excitable y lógica fuzzy en los medios argentinos de comunicación
}

\author{
Dr. Hugo Hortiguera. \\ Griffith University. Australia.
}

\begin{abstract}
-Posible, pero no interesante- respondió Lönnrot-. Usted replicará que la realidad no tiene la menor obligación de ser interesante. Yo le replicaré que la realidad puede prescindir de esa obligación, pero no las hipótesis. En la que usted ha improvisado interviene copiosamente el azar. He aquí un rabino muerto; yo preferiría una explicación puramente rabínica, no los imaginarios percances de un imaginario ladrón.
\end{abstract}

Jorge Luis Borges. 'La muerte y la brújula'.

'Las ficciones orientadoras de las naciones [...] suelen ser creaciones tan artificiales como ficciones literarias', nos decía Nicolás Shumway en un estudio muchas veces citado. ${ }^{1} \mathrm{Y}$, aludiendo a un trabajo de Edmund Morgan, observaba que resultaban positivas, por cuanto provocaban un impulso para que la realidad se amoldara a la ficción orientadora de la representación, consolidándose, a la vez, un sentimiento colectivo de identidad.

A lo largo de la historia argentina del último siglo, cierto tipo de frases altisonantes de algunos sectores de la clase política parece ejemplificar con mucha precisión esta observación. Así, se recordará cómo ya en 1901 Bartolomé Mitre afirmaba que 'la grandiosidad del futuro [era] "una fatalidad escrita en nuestra carta geográfica"'.2 Recordemos, por otra parte, el famoso 'destino de grandeza de la nación argentina', expresión utilizada por el General Perón en muchas de sus alocuciones. O tengamos en cuenta la reiterada afirmación menemista de que la Argentina pertenecía -casi por decreto- al primer mundo. Pensemos también en 'Los argentinos estamos condenados al éxito’, del presidente interino Eduardo Duhalde durante los primeros meses de 2002, para transmitirle al pueblo su optimismo en las negociaciones con el Fondo Monetario Internacional, en medio de uno de los momentos políticos más críticos de su historia reciente. Y por último, mencionemos el mucho más cercano: 'Somos víctimas de nuestro propio éxito económico’, de Alberto Fernández, jefe de gabinete de la presidenta Cristina Fernández de Kirchner, en enero de 2008, para justificar los incesantes cortes de luz en la ciudad de Buenos Aires durante ese caluroso verano. 
Sin embargo, en la Argentina contemporánea, este constante juego entre la vehemencia de las palabras oficiales, la imagen que los medios daban de su sociedad y la decadencia que el ciudadano promedio vivía a diario en su deambular por las calles de sus ciudades parecía instaurar una dinámica de conflicto que se extendía a todos los niveles. Se ponía en evidencia una brecha insalvable que existía entre el orden de lo real y un discurso político-mediático que se empeñaba en hacer una lectura exaltada, grandilocuente y cuasi mitológica de su entorno. ${ }^{3}$

Sin duda, los relatos que los medios argentinos han ido desarrollando sobre el país en los últimos ocho años parecerían haber exacerbado este particular sentido retórico, cuyo punto de inflexión tal vez podría remontarse a las dos presidencias del Dr. Menem (1989-1999). Apelando en forma descarada a procedimientos ficcionales emparentados en muchas ocasiones con lo policial, estas manipulaciones textuales aparecerán cruzadas por complejas operaciones verbales que servirán como clave para entender la idea que se intentó perpetuar sobre la nación en uno de sus momentos de mayor incertidumbre política. Así, una relectura de los procedimientos y corrimientos discursivos que muchas de estas narraciones pusieron en práctica ayudaría a comprender la extensión y efectos de este fenómeno. ${ }^{4}$

\section{‘Qué esperamos agrupados en la plaza?’}

Como bien observa Castoriadis, uno de los elementos que más ha influido en la crisis general de las sociedades de Occidente estaría dado por el conflicto que se establece con las significaciones imaginarias sociales, por cuanto éstas, como nota, son 'el factor de cohesión de la sociedad'. ${ }^{5}$ En este sentido, la construcción de ciertas narrativas mediáticas y su difusión y cruzamiento con las culturas populares podrían ser elementos claves para entender semejante desequilibrio. ${ }^{6}$

Y, en verdad, como señalan Aníbal Ford y Silvio Waisbord siguiendo a Benedict Anderson, las instancias mediáticas han tenido un rol pivotal en la perpetuación de ciertas representaciones que una determinada sociedad tiene sobre sí misma. ${ }^{7}$ Será a través de ellas que dicha comunidad irá forjando su propia identidad, al asignar papeles y roles sociales y difundir sus creencias. Y en este proceso de conformación de su identidad colectiva se irá delimitando su territorio y su relación con los otros. ${ }^{8}$ 
Como se recordará, durante los '90, la Argentina sufrirá, en un muy corto plazo, una concentración brutal de medios de comunicación. En efecto, será a partir de la segunda parte de esa década, cuando, gracias a las medidas privatizadoras llevadas adelante por el gobierno del Dr. Carlos Menem, se afianzarán en el país grandes holdings mediáticos, asociados, muchas veces, con capitales extranjeros. En tanto, el menemismo, entendido ahora como modelo económico-político, se consolidará y chocará con los efectos de la globalización. Pronto, la expansión cada vez más poderosa de las empresas privadas de comunicación y las crecientes inversiones de capitales extranjeros en el medio enfrentarán una serie de crisis económicas sucesivas: el 'efecto tequila' de diciembre de 1994 -con la crisis de los mercados mexicanos-; la debacle asiática de 1997; el default ruso de 1998; y, más recientemente, el default argentino de 2001, hechos todos que traerán aparejados una retracción del mercado nacional y una reducción considerable del consumo. ${ }^{9}$

Este descalabro económico, no obstante, no impidió que se detuviera la tendencia de inversionistas extranjeros en los medios argentinos de comunicación. El usufructo del espacio mediático nacional quedaba así sujeto a sistemas de 'disciplinamiento' y globalización de los capitales internacionales, redefiniendo de esta forma el mapa político-económico de la Argentina del nuevo siglo. ${ }^{10}$ Asimismo, con el fin de evitar una catástrofe comercial, los medios de comunicación debieron rápidamente ajustar algunas de sus estrategias comerciales y, de esta manera, incrementar la audiencia, producir el mayor efecto y legitimar su naciente poder en la nueva sociedad. ${ }^{11}$

Y es en este punto en el que me gustaría detenerme en este documento. En efecto, a esta combinación de capitales con socios locales que mencionaba más arriba, le seguiría, en paralelo y en el terreno discursivo, una fusión de géneros y contenidos que pareciera diluirse en el tejido textual y conformar narrativas mucho más confusas e híbridas, en donde los mismos bordes o fronteras genéricas aparentan difuminarse. Nos encontramos así ante la necesidad de reevaluar las categorías organizativas de algunos de los contenidos mediáticos argentinos, por cuanto, coincidiendo con van Dijk, quién y cómo regula el discurso público, 'controla indirectamente la mente (incluida la ideología) de las personas y, por lo tanto, también sus prácticas sociales'. 12 
En lo que queda de esta presentación, ejemplificaré algunas estrategias mediáticas que se fueron apoderando con fuerza del tejido cultural de estos años e intentaron reordenar la sociedad, ajustándola a esta nueva lógica. Este fenómeno complejo terminó provocando corrimientos significativos en la construcción enunciativa de algunos géneros textuales.

\section{'Hay golpes en la vida tan fuertes...'}

Una de las estrategias mediáticas más frecuentes fue la construcción de una galaxia de 'operadores de sentido' que explicaba la realidad nacional en términos de 'thriller folletinesco'. ${ }^{13}$ Desde esta perspectiva, la confluencia de una temática policial y la estructura folletinesca funcionó como mecanismo recurrente, económico y ‘estetizante’ que les permitía a los medios proveer sentido a su audiencia siempre dentro de lógicas de reconocimiento accesibles y muy acotadas.

En este sentido, el gesto de muchas de las historias mediáticas que circularán por estos años girará siempre alrededor de motivos conexos: caos, vendettas personales, corrupción y delito serán parte integral de la estructura del poder argentino y desde allí irradiarán al resto de la sociedad. En verdad, cada una de las noticias publicadas por los diferentes canales mediáticos, fuertemente cruzadas por la casuística y la sinecdoquización, conformarán un discurso de 'descomposición social irreversible', de ausencia de moralidad que se esparce por doquier. ${ }^{14}$ Por otra parte, la reiteración incesante de casos similares y la irresolución de cada uno de estos conflictos destacarán no sólo la fragilidad del edificio social sino también la incapacidad del estado nacional democrático para manejar y controlar esos excesos. Este fenómeno incrementará el clima de descontento social y descreimiento público en las instituciones, instigando, en forma indirecta, a producir formas de control social formales o informales- que terminarán tratando más con los efectos que con las causas. $^{15}$

Un ejemplo notable de esta práctica puede verse en el tratamiento que le dio la prensa a la muerte del hijo del ex-presidente Menem y a todas las hipótesis y teorías que movilizó en su momento. Recordemos el caso. En la mañana del 15 de marzo de 1995, Carlos Saúl Menem (h) se accidentó mientras viajaba en un helicóptero junto con su amigo Silvio Oltra, piloto de autos de competición, en las cercanías de la 
ciudad de Ramallo (Provincia de Buenos Aires). Oltra murió en el acto, mientras que Menem Junior logró sobrevivir en estado de coma por unas horas. Sin embargo, la línea del accidente -confirmada por varios testigos presenciales- comenzó pronto a ceder su espacio a otra interpretación que parecía mucho más seductora, habida cuenta del personaje involucrado. En efecto, fomentada por las insinuaciones de la madre de la víctima, la teoría de un atentado se difundió por la prensa, con relatos de conspiraciones y vendettas personales sin ninguna prueba seria que la respaldara. Se llegó a dudar de la identidad del cuerpo sepultado e inclusive se habló en repetidas oportunidades de profanaciones que habrían sufrido los restos del joven en su autopsia. La historia continuó en forma intermitente en los medios durante casi dos años, hasta que el 3 de julio de 1997, Radio Mitre (perteneciente al poderoso grupo Clarín) puso al aire una llamada anónima en la que un desconocido afirmaba haber oído las últimas palabras de Menem Junior antes de morir. En ellas, informaba, el joven aseguraba haber sido blanco de un atentado. Sin embargo, nada pudo probarse y su veracidad fue puesta en duda.

El caso siguió, entonces, un derrotero muy particular, con la inclusión de curiosos personajes que denunciaban conspiraciones varias: un albañil peruano autoproclamado 'narcoguerrillero colombiano' -entrevistado por la revista Tres Puntos y por periodistas de Telefé Canal 11-; un espía de la Secretaría de Información del Estado (SIDE), quien acusaba a la Mossad del supuesto asesinato; y hasta la madre del muerto, quien ahora insistía en poner en duda la verdadera identidad del cadáver sepultado en el cementerio islámico. Durante la causa judicial apareció también toda una serie de personajes -algunos de ellos, se sugirió más tarde, pagados por los medios- con acusaciones aún más delirantes. La causa se complicó a partir de las muertes de seis testigos o personas involucradas en la investigación entre 1995 y 1997. Todo esto llevó a la prensa a especular sobre una conspiración para acallarlos, aunque luego se demostrara que las muertes nada tenían que ver con el caso. ${ }^{16}$

De más está decir que, hasta la fecha, ninguna investigación judicial logró jamás probar ningún asesinato y la muerte del hijo del presidente quedó caratulada oficialmente como accidente. Sin embargo, pese a lo determinado por la justicia, la prensa mantuvo la hipótesis del atentado. Al fin de cuentas, la noticia tenía todos los clichés exagerados y rumbosos para armar una historia convenientemente literaria y 
'vendible’: el joven playboy del subdesarrollo y de origen islámico, su conexión con el poder, su inclinación por los deportes peligrosos, sus relaciones con el universo de los 'ricos y famosos', las referencias al mundo de los espías, y hasta la casi telenovelesca 'sustitución del cadáver' (motivo que veremos reaparecer en el caso Yabrán de 1998). ${ }^{17}$ Todo estos elementos permitían explicar su accidente dentro del marco de una lectura disfuncional de la sociedad, al tiempo que corroboraban el humor y las sospechas de la opinión pública respecto de la corrupción generalizada. El escándalo se apropiará de la escena de los medios, de su espacio, y, como tal, será percibido como un síntoma más de las transformaciones culturales por las que atravesaba el país. En otras palabras, la presunción del asesinato se volvía creíble porque le permitía a la audiencia verificar una hipótesis de descomposición moral. ${ }^{18}$

Este ejemplo resulta de utilidad porque nos permite ver cómo algunos operadores de sentido (el 'ajuste mafioso' o la 'mafia’) se irán apoderando de los titulares y notas periodísticas, como una forma económica y efectista que la instancia mediática encontró para poder definir el momento político-social y relacionar casos lejanos -en el tiempo y el espacio- dentro de una serie mayor. Así, estos conceptos adquirirán un valor de 'comodín’ que terminará siendo útil para explicar cualquier otra situación delictiva o irregular: se hablará así de la mafia empresarial, política, judicial, y hasta futbolística. ${ }^{19}$ Semejante concepto será altamente productivo para los multimedios argentinos recientemente conformados, y funcionaría como el 'mecanismo del secreto' típico de las telenovelas, del que ya ha hablado Lucrecia Escudero en su momento. ${ }^{20}$ La recurrente apelación al concepto de 'mafia' (como lógica del funcionamiento de lo social) desencadenará una estrategia de producción de un efecto dilatorio: la búsqueda de un saber oculto (la agnición o reconocimiento de la identidad de los involucrados en la[s] sociedad[es] secreta[s]) que, en el contexto argentino, nunca se produce.

Esperando ese momento, el lector redoblará su fidelidad con los medios (o con los multimedia a los que esos medios pertenecen), al seguir a diario una revelación que se promete y se pierde en su serialización. Y esto no es difícil de entender, si tenemos en cuenta que en esos momentos -segunda parte de los ‘90- la crisis económica hacía estragos y los nuevos conglomerados peleaban palmo a palmo por posicionarse en un mercado cada vez más inestable. En este sentido, no podemos soslayar la particular 
retroalimentación de noticias que esos mismos grupos mediáticos producían entre las ediciones de sus periódicos, sus programas matutinos de radio (que las leían y expandían) y sus noticiarios (de televisión abierta y cable) que las retomaban a la noche, hasta reiterarse todo el proceso otra vez al día siguiente. ${ }^{21}$

Es así que en cada componente del universo multimediático se exponía un nuevo capítulo de una gran saga, con vueltas de tuerca inesperadas, conexiones imprevistas, suspenso y cliffhangers incluidos que se continuaban en los otros. Se conformó pues un modelo muy particular de circularidad de la noticia que, como señala Fernández Pedemonte, bordeaba con peligro el sensacionalismo. ${ }^{22} \mathrm{Y}$ esto no se daba tanto por sus alusiones a la emoción sino por su evidente falta de reflexión, fenómeno que terminaría afectando la calidad informativa de lo publicado. La ausencia de pruebas y de una reflexión estructural de los problemas empañaba muchas veces la seriedad de las noticias, cuyo único respaldo de credibilidad podía estar dado por el contrato de lectura que el lector había establecido con el medio en algún momento del pasado. En este sentido, vale la pena hacer notar cómo la exacerbación de la fuente anónima o la simple ausencia de fuentes en muchas notas de los llamados ‘diarios serios' comienza a acentuarse de manera notable durante este período. ${ }^{23}$

Este fenómeno se repetirá una y otra vez: en el suicidio del empresario Alfredo Yabrán (1998); en el caso de la corrupción en el senado, escándalo con el que se acusó a senadores nacionales de haber recibido sobornos para aprobar una nueva ley laboral (2000); en el asesinato de María Marta García Belsunce en su casa de un barrio cerrado en las afueras de Buenos Aires (2002) (irresuelto hasta la fecha, pero transformado en 'drama de corte' en las ediciones periodísticas de junio de 2007, durante el juicio al esposo de la víctima); en el famoso caso del robo al Banco Río en la provincia de Buenos Aires en enero de 2006; o en el mucho más reciente caso Dalmasso -de similares características al de Belsunce- de $2006 .^{24}$

Una promiscuidad discursiva se apropiará de las narraciones. En ellas, la ficción parecía empeñada en querer confirmar ciertos aspectos de la realidad, como si ella pudiera explicarse sólo mediante mecanismos ficcionales, y convocar hipótesis posibles, pero no necesariamente reales. Se creaba un proceso sincrético complejo, 
una amalgama de estos dos dominios, dando lugar a una 'estética fuzzy' que no distinguía bordes ni fronteras. ${ }^{25}$

\section{'Vivimos revolcaos en un merengue...'}

Uno de los ejemplos más interesantes del uso de la ficción, por las repercusiones que tendrá en otros ámbitos del quehacer cultural, está dado por el uso que Clarín hizo para describir el caso de María Marta García Belsunce (de 2002), del que ya se ha dado cuenta ampliamente en otro lugar y no voy a entrar en detalles aquí. ${ }^{26}$ Pero sí quisiera mencionar cómo ese mismo periódico incorpora la ficción para, una vez más, relatar un caso que, por sus características, había conmocionado a la opinión pública. A partir del 26 de enero de 2003, y por casi un mes, el matutino publicó una serie de artículos ficcionales firmados por el escritor Vicente Battista, en donde comentaba, desde la perspectiva de un matrimonio de clase media, las pistas y novedades del caso policial. Los artículos aparecían dos veces por semana al lado de las noticias que día a día se conocían del asesinato. En ellos, estos personajes de ficción se entretenían estipulando hipótesis, sugerían líneas de investigación, analizaban las pistas y discutían posibles motivos (siempre en medio de referencias literarias que les permitían, por un lado, pasar revista a las reglas del género policial y, por otro, establecer comparaciones del caso Belsunce con algunos de esos productos ficcionales clásicos).

El fenómeno lo reiteró Página/12 más recientemente, al conocerse la decisión de un tribunal de justicia de sentenciar al esposo de la víctima a cinco años de prisión por encubrimiento en su asesinato. Al día siguiente de la sentencia (12 de julio de 2007), el periódico no titubeó en publicar una entrevista al escritor Vicente Battista (transformado ahora, gracias a toda esta convocatoria mediática, en EL escritor de policiales). En ella se le pedía al autor, otra vez, un análisis del caso en 'clave de novela policial' ${ }^{27}$

Sin duda, este recurso de incluir la ficción descarada al lado de las crónicas debe haber funcionado muy bien para los periódicos. En efecto, Clarín reitera el mismo procedimiento el 16 de enero de 2006, para el caso del robo en la sucursal del Banco Río, con la reproducción de un texto ficcional de Walter Slavich (guionista de los programas de televisión Mujeres asesinas, Sin código -los dos de Canal 13, 
perteneciente al grupo Clarín- y El garante, de Canal 9) en donde se contaba una posible hipótesis de los acontecimientos que rodearon el asalto y un probable desenlace. ${ }^{28}$ ¿Cómo leer entonces cada noticia del caso que se sucedía en las siguientes ediciones? ¿Dentro de qué parámetros colocarse? Un 'efecto de contigüidad' con lo ficcional terminará por empañar cualquier acercamiento a la noticia, al hecho real.

Mucho más cerca aún, en enero de 2007, en el caso Dalmasso se efectuará un proceso similar al de Belsunce. Así, aprovechando el creciente interés de la audiencia por esta historia, que contenía extrañas similitudes con aquella -al punto de que algunos titulares parecían repetirse-, el matutino porteño La Nación dará un paso más allá. Convenientemente, las crónicas del caso comenzarán a evocar dentro de su diégesis las historias de varias novelas policiales clásicas, mientras que diversas notas de su suplemento cultural reproducirán estudios sobre el género policial (fenómeno que ya se había dado también en el caso Belsunce). No satisfecho con esto, el diario incluirá en su edición de los días miércoles una colección literaria con los libros más emblemáticos de Agatha Christie, los cuales podían comprarse por separado. La noticia del asesinato se convertía así en un impactante y desembozado impulso para promocionar una nueva actividad comercial del periódico.

Semejantes intentos parecieran haber sido muy exitosos como forma de atraer lectores y servido de prolegómenos para que, ya el domingo 24 de febrero de 2008, Clarín institucionalizara un espacio en su edición dominical. Será a partir de esa fecha que el diario dará lugar en su suplemento Zona a una sección titulada 'Zona de autor', la cual se proponía como un ámbito de 'reflexión y relatos a cargo de prestigiosos escritores y periodistas que, a mitad de camino entre ficción y realidad, ensayan nuevas formas de narración, a partir de hechos, situaciones y protagonistas de las miles de historias que nacen y mueren día a día'. ${ }^{29}$

La primera de esas columnas aparecía firmada por Claudia Piñeiro, una relativamente conocida escritora, guionista de TV y colaboradora de distintos medios gráficos que, en 2005, había ganado el premio Clarín-Alfaguara de novela con Las viudas de los jueves, texto policial ambientado en un barrio cerrado en las afueras de Buenos 
Aires. ${ }^{30}$ Curiosamente, a fines de 2007, el mismo sello editorial Clarín-Alfaguara publicaría otra novela policial de la misma autora: Elena sabe. La apelación a Piñeiro para inaugurar esa columna unas semanas más tarde de salir a la venta su libro en un sello editorial propiedad del mismo diario, entonces, no podía ser fruto de la casualidad.

Un espacio conflictivo entre mundos y lógicas distintas se instalaba así en el terreno comunicacional: un mundo fictivo y otro factual; una lógica descaradamente comercial y de captación, y otra de información. ${ }^{31}$ Es evidente que la diversificación de la producción de los grandes holdings y el énfasis desmedido en el enfoque empresarial influyó en los sistemas de gestión de la prensa, provocando, como hemos visto, un tejido textual que atravesará dos campos: el entretenimiento y la información. En este sentido, podríamos afirmar que se terminaba recurriendo a un principio de complementariedad por el cual se apelaba a distintos usos de un mismo 'producto' o se utilizaban 'los mismos factores de producción para realizar bienes diferentes'. 32

Así, veremos cómo todo este clima de thriller folletinesco, convenientemente estimulado desde el espacio mediático, contribuirá, en los últimos años, a promover el género policial en el mercado. Y lo harán no sólo en el terreno de la llamada ‘investigación periodística’ (prolífica en este período, por otra parte), sino también en el campo de la ficción. En efecto, muchos nuevos textos literarios que se producen dentro de este género serán premiados en 'concursos' organizados por los grandes diarios -los de Clarín y La Nación son los más famosos- o por las editoriales relacionadas con los mismos grupos económicos. El libro premiado será luego publicado con una importante tirada por la editorial del grupo, promocionado en todos los programas de TV y radio de las mismas empresas y reseñados ampliamente en las páginas de los suplementos culturales de esos mismos matutinos. Algunos de ellos serán llevados al cine y su banda de sonido será grabada en las mismas compañías grabadoras pertenecientes o asociadas al multimedia, para terminar reseñados, una vez más, en las páginas de espectáculos de esos mismos matutinos, o difundida su música en las radios del grupo. 
Veamos algunos ejemplos. A los ya mencionados textos de Piñeiro, se pueden agregar -con desigual calidad- los textos de Marcelo Figueras, El espía del tiempo (2002); Guillermo Martínez, Crímenes imperceptibles (2003) -llevada recientemente al cine como Los crímenes de Oxford-, y La muerte lenta de Luciana B. (2007); Alejandro Vaccaro, El manuscrito Borges (2006); Martín Caparrós, Valfierno (2004), premio Planeta de ese año -cuya historia cuenta un caso real de delito internacional ambientado en 1911-; Carlos Balmaceda, con su Manual del caníbal (2004) y El puñal de Dido (2006); y Pablo de Santis, con El enigma de París (2007), premio Planeta-Casamérica de ese año.

En otros casos, la página policial de los matutinos será también el detonante de muchos productos literarios, impulsados o escritos por periodistas. Tales son los casos, por ejemplo, de Mujeres asesinas (2000), texto escrito por Marisa Grinstein, periodista de la sección política de la Revista Noticias, que contenía catorce historias de asesinatos reales cometidos por mujeres en Argentina; Un crimen argentino (2002), del periodista Reynaldo Sietecase, basado en un famoso crimen de los '80; o la antología Escritos con sangre (2003), de Sergio Olguín (periodista de Página/12), en donde cada cuento, escrito por periodistas o autores consagrados del género, tomaba un 'caso policial' real. ${ }^{33}$

Tampoco podemos olvidar de mencionar la colección "Policiales reales” que Editorial Planeta, aprovechando toda esta promoción del género en el mercado, publica a partir de 2007, con una serie cuyos títulos son un compendio de los casos policiales más resonantes de la última década: El caso Belsunce, El caso Barreda, o El golpe al banco Río, de Ricardo Canaletti y Rolando Barbano. Otros ejemplos pueden encontrarse en El crimen de la dama del Pilar. La verdadera trama del asesinato de María Marta García Belsunce (2007), de Maricarmen Almada (periodista de Página/12 y Revista Veintitrés) y en su otro trabajo El crimen Bordón (2001) que escribiera con Silvia Licht; o las antología de 'estudios' sobre casos criminales reales No somos ángeles. Historias secretas al filo de la ley (2007) de Liliana Caruso, Florencia Etcheves y Mauro Szeta (periodistas de Canal 13, Diario Popular y Clarín) o Crímenes en familia. Siete casos que conmovieron a la Argentina (2007), de Cynthia Ottaviano. 
Párrafo aparte merece la adaptación de la novela de Alejandro Dumas, El conde de Montecristo, que para la TV argentina hicieran los guionistas Adriana Lorenzón y Marcelo Camaño. Por motivos de espacio, no me podré extender sobre este asunto, de por sí, muy interesante, pero vale la pena recordar algunos elementos. La telenovela, titulada Montecristo. Un amor, una venganza, éxito de público en la temporada 2006, fue emitida por Canal 11 Telefé y en ella se contaba, con el trasfondo del terrorismo de estado de los años 70, una historia policial que mezclaba los desaparecidos, la apropiación de bebés y el juicio a torturadores. A caballo del éxito televisivo, Canal 11 pronto decidió publicar, en asociación con los sellos Aguilar-Altea-TaurusAlfaguara, la adaptación escrita de esa telenovela que, con el mismo título, apareció en las librerías argentinas en 2006.

De la literatura a la televisión -previo paso por las páginas policiales locales- y de ésta a la literatura otra vez. El thriller folletinesco ejecutaba un movimiento perfecto, en un juego convergente en donde la literatura popular, las páginas de los periódicos y la historia argentina reciente confluían y se cruzaban entre las distintas subsidiarias de los conglomerados mediáticos, complementando entre sí sus distintos emprendimientos comerciales. $^{34}$

En este sentido, por lo que he venido describiendo, la recurrencia al thriller folletinesco fue una apuesta muy sofisticada detrás de la cual se escondían fuertes intereses económicos que buscaban integrar el entretenimiento y la información (al fin de cuentas, estos nuevos holdings tenían y tienen importantes inversiones en la industria del entretenimiento). Se provocaron así profundos vínculos emocionales que fueron útiles para aumentar las ventas no sólo del periódico en sí, sino de las otras subsidiarias del conglomerado. $\mathrm{Y}$ en esta insistencia alrededor del eje de la serialización del crimen y el delito radica la particularidad del caso argentino. Como vimos, la industria editorial terminó promoviendo libros cuyos temas -de ficción, no ficción e investigación- giraban alrededor de los casos más resonantes que la misma empresa periodística del grupo había exaltado. Mientras tanto, las productoras cinematográficas o televisivas del mismo conglomerado producían películas, series y telenovelas que dramatizaban algunos de estos casos. El tema, así, no pasaba tanto por el hecho de que la audiencia estableciera una relación única con una de las compañías, sino que mantuviera una relación de fidelidad a largo plazo con el holding in toto, 
gracias al hilo conductor en que se había transformado el género que se difundía a través de las distintas plataformas (para el caso de Clarín, por ejemplo, esto significaba Canal 13, sus canales de cable, radio Mitre, sus editoriales, productoras de cine y televisión, Internet, telefonía, etc.). Si los nuevos consumidores, como señala Jenkins, son migratorios y predecibles, estos mecanismos les ofrecían una seducción y atracción muy difícil de resistir. ${ }^{35}$

En una palabra, el thriller folletinesco se transformó en Argentina en una especie de género transmediático (o un 'transgénero’, en palabras de Steimberg) que le ofrecía al lector participar de nuevas experiencias y emociones, mientras desdibujaba la línea entre realidad y ficción. ${ }^{36}$ Se le brindaba a la audiencia un flujo constante de dramas policiales que se expandía como una mancha de aceite entre las distintas empresas del conglomerado, generando pánico y alentando formas de percibir y vivir la ciudad -y por extensión el país- de un modo mucho más temeroso. Semejante dinámica terminó siendo funcional a las lógicas más conservadoras de mano dura y control social y abrió las puertas para aceptar sistemas de castigo más rígidos y severos.

\section{'Continuará...'}

En varias oportunidades se ha señalado que la desaparición del espesor simbólico del Estado-Nación pareciera acentuarse en forma dramática a partir de los '90 con la consolidación de la ideología neoliberal, la concentración de grupos económicos y un régimen de discurso único y globalizador. ${ }^{37}$ Semejante fenómeno tendrá su correlato en la conformación de un ámbito discursivo mediático sin fronteras, borroso, sin ley (de género), en donde realidad y ficción se ubicarán así en una zona lábil.

Este espacio inestable de fusión se amoldará muy bien a las nuevas necesidades del mercado y será uno de los procesos claves para entender la particular estrategia discursiva de estos años. En ella, mediante ciertos procedimientos de composición, se hará visible un doble deseo de simplificación y dramatización que entrañaría, en última instancia, reconsiderar los viejos supuestos sobre el consumo mediático. Y en esta amalgama compositiva, la idea de entretenimiento será pivotal como fórmula de máxima eficacia para conquistar y mantener audiencias, disciplinadas ahora en una dirección particular de lectura de la realidad. En ésta, el thriller folletinesco tendrá un 
lugar destacado, instalando en la audiencia, como efecto colateral, un miedo irracional que coadyuvaría a fomentar una sensación de precariedad social. En una palabra, esta focalización redundante en la criminalidad y el delito, que se expresará a través de una variada gama de productos culturales de la época, terminará promoviendo una sensación permanente de amenaza a la seguridad física de los ciudadanos y sus bienes, generando una onda de pánico expansiva.

Como el rey Sahrayar con Sherezade, el receptor -lector, telespectador, radioescuchaesperará con ansiedad un nuevo capítulo de 'la gran novela argentina’ que los medios se ocuparán de contarle todos los días. Mucho más interesados ahora en mantener la conexión, los holdings mediáticos buscarán cautivar su atención y acrecentar ventas para mantenerse a flote, antes que informar u opinar con precisión. Se privilegiará así una práctica discursiva en donde se conjugarán, por un lado, elementos fácilmente reconocibles y extraídos de la propia realidad con estructuras narrativas particulares y muy populares que terminarán por banalizar la información, enturbiar su relación con la verdad y convertir al ciudadano ‘en pura audiencia ante el Teatro de la República, 38

Gracias a esta apelación insistente y particular al thriller folletinesco que venimos mencionando -como especial del contexto argentino-, se impulsará la creación de una narrativa macro que construirá un mundo 'espectáculo’ cruzado por lo siniestro, lo azaroso y lo inaudito dentro del ámbito nacional. Estos operadores de sentido no sólo controlarán el discurso mediático, sino también, como hemos visto, la difusión del arte culto y popular de estos años. Y serán los placeres del exceso escandaloso, la corrupción y el desorden que, gracias a la práctica que he descrito, se perfilarán en el imaginario de la época como el carácter esencial de una sociedad desmesurada que se debate, todavía, entre los espectros de su pasado y los espejismos de su futuro.

\section{Notas}

1 Nicolás Shumway, La invención de la Argentina. Historia de una idea, Buenos Aires, Emecé, 1995, p.13.

${ }^{2}$ Adrián Gorelik, Miradas sobre Buenos Aires. Historia cultural y crítica urbana, Buenos Aires, Siglo Veintiuno, 2004, p.31.

3 'En sociedades en vías de mediatización (Verón 1987), los medios podían pensarse como vehículos de circulación de información necesaria para el procesamiento cívico. En la actualidad, como resultado de una articulación triangular entre los medios de comunicación, el poder político y la ciudadanía, los ciudadanos de las sociedades mediatizadas (ib.) quedan confinados a un espacio político en el que la 
acción refrenda o invalida las ambiciones de los integrantes de la hegemonía. La interlocución que se postula coloca a los ciudadanos en un lugar cuya participación se limita a la opinión’. Lila Luchessi y Graciela María Rodríguez, 'Espacio y representaciones en la cultura, la política y los medios', en Lila Luchessi y Graciela María Rodríguez (eds), Fronteras globales. Cultura, política y medios de comunicación.. Buenos Aires, La Crujía, 2007. pp. 9-25, (p.11). (Subrayados en el original).

${ }^{4}$ No es mi intención aquí extenderme en un estudio sobre la estética menemista -tema que, por lo demás, excedería mi trabajo-, ni estudiar las llamadas 'tácticas de resistencia’ de la audiencia. Mi objetivo específico es documentar sobre las formas más evidentes de expresión e interacción entre medios que se fueron desarrollando en Argentina a partir de la conformación y expansión del nuevo universo mediático. Para un lector interesado en un panorama del período menemista y su estética, la bibliografía es extensísima. Como introducción, recomiendo Luciana Vázquez, La novela de Menem. Ensayo sobre la década incorregible, Buenos Aires, Sudamericana, 2000; Luis Alberto Quevedo, 'Políticas, medios y cultura en la Argentina de fin de siglo', en Daniel Filmus (ed.), Los noventa: política, sociedad y cultura en América Latina y Argentina de fin de siglo, Buenos Aires, FLACSOEudeba, 1999, pp.201-224; Beatriz Sarlo, 'Argentina under Menem: the Aesthetics of Domination (Report on Culture)', NACLA Report on the Americas 28.2, 1994, pp.33-37; Hugo Hortiguera y Carolina Rocha (eds), Argentinean Cultural Production During the Neoliberal Years (1989-2001), New York, The Edwin Mellen Press, 2007; Hugo Hortiguera, 'De la investigación periodística al potin: El relato documental argentino de fin de siglo’. The Space of Culture. Critical Readings in Hispanic Studies. Stewart King y Jeff Browitt, Newark, Universisty of Delaware P., 2004, pp. 118-141. Para un acercamiento al estudio de las audiencias en el presente contexto, remito a Damián Fernández Pedemonte, La violencia del relato. Discurso periodísitico y casos policiales, Buenos Aires: La Crujía, 2001; Mar de Fontcuberta y Héctor Borrat, Periódicos: Sistemas complejos, narradores en interacción, Buenos Aires, La Crujía, 2006; Lila Luchessi y María Graciela Rodríguez (eds.), Fronteras globales; Lucrecia Escudero Chauvel y Claudia García Rubio, Democracias de opinión. Medios y comunicación política, Buenos Aires, La Crujía, 2007, entre otros.

${ }^{5}$ Cornelius Castoriadis, El avance de la insignificancia. Buenos Aires, Eudeba, 1997, p.251.

${ }^{6}$ 'Los medios de comunicación juegan un papel relevante en la construcción de los imaginarios sociales ya que, al producir bienes simbólicos, aportan a la construcción que esa sociedad hace de su imaginario. Los imaginarios sociales son las representaciones (mitos, memorias, “arquetipos”, etcétera) que una determinada sociedad o comunidad tiene de sí misma o de otras’ (Aníbal Ford, La marca de la bestia. Identificaciones, desigualdades e infoentretenimiento en la sociedad contemporánea, Buenos Aires, Norma, 2002, p. 64). Cf también Aníbal Ford, Navegaciones. Comunicación, cultura y crisis, Buenos Aires, Amorrortu, 2001, p.161.

${ }^{7}$ Ford, La marca, p. 64 y Silvio Waisbord, 'Los medios y la reinvención de la Nación', en Luchessi y Rodríguez (ed), Fronteras globales, pp. 29-63 (p. 33).

8 'Los medios están en el centro de su discutida idea [de Anderson] de las naciones como 'comunidades imaginadas’. [...] Anderson estuvo más interesado en comprender por qué cada nación fue "imaginada" en cada momento de los procesos socio-económicos en relación con los intereses específicos de la clase. Estas diferencias son expresadas en sus argumentos acerca del rol de los medios en el origen de las naciones’ (Waisbord, 'Los medios', pp. 32-33).

${ }^{9}$ Para mayores detalles sobre la configuración oligopólica de este período ver Jorge Castro y Ricardo Petraglia, 'Conformación oligopólica de las Telecomunicaciones en la República Argentina: otra muestra de la realidad latinoamericana El mercado en pocas manos’, Sala de Prensa 33, 2, 2002, < http://www.saladeprensa.org/art239.htm>. En lo que se refiere al descenso en la venta de los periódicos argentinos, la Asociación Mundial de Periódicos (WAN) señalaba que la Argentina presentaba, para el período 1997-2001, la caída más pronunciada en todo el mundo, con un retroceso del 35,8\% (Ver Federico Rey Lennon, 'Crisis de la prensa argentina', Chasqui, 80, 2002,

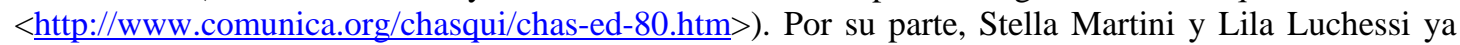
observaban la disminución notable en la circulación de los diarios nacionales en el período 1999-2004. De acuerdo con ellas, esto podría explicarse, por un lado, como una consecuencia lógica de la recurrente crisis económica, la del sistema político -que había despertado un desinterés de la sociedad por leer la información que éste producía-, y, por otro, por la influencia poderosa que radio y televisión ejercían sobre la población para posicionarse como la fuente más habitual de acceso a las noticias. Para mayores detalles sobre este punto, ver Stella Martini y Lila Luchessi, Los que hacen la noticia. Periodismo, información y poder, Buenos Aires, Biblios, 2004, pp. 77-78. Para una brevísima revisión histórica y cultural de este período ver también Hugo Hortiguera y Carolina Rocha (eds), Argentinean Cultural Production, pp. 1-20. 
10 'Es innegable que en las últimas décadas la intensificación de las relaciones económicas y culturales con los Estados Unidos impulsa un modelo de sociedad donde muchas funciones del Estado desaparecen o son asumidas por corporaciones privadas, y donde la participación social se organiza a través del consumo más que mediante el ejercicio de la ciudadanía' (García Canclini, citado por Ana María Zubieta, Oscar Blanco, Marcela Domine, et al., Cultura popular y cultura de masas. Conceptos, recorridos y polémicas, Buenos Aires, Paidós, 2004, p.246). Se recordará así que en 1997 el Citicorp Equity Investment (CEI) hará su aparición en el ámbito mediático argentino, comprando -en sociedad con Telefónica Internacional (de España)- parte del paquete accionario del grupo Atlántida Comunicaciones (que incluía Editorial Atlántida, Radio Continental y Telefé [Canal 11]). Algo similar ocurrirá con Prime Television (de Australia), CEI y un grupo de empresarios locales respecto de Canal 9 de la capital y otros canales del interior. La misma historia se repetirá con emisoras de televisión por cable (Cf. Adriana Schettini, Ver para creer. Televisión y política en la Argentina de los 90, Buenos Aires, Sudamericana, 2000, p.68).

${ }^{11}$ Néstor García Canclini, Ideología, cultura y poder, Buenos Aires, Oficina de Publicaciones del CBC, Universidad de Buenos Aires, 1997, p.29.

12 Teun A. van Dijk, Ideología y discurso. Una introducción multidisciplinaria, Madrid, Ariel, 2003, p.48. Para la noción de 'género', sigo a Martín-Barbero cuando afirma que 'no es algo que le pasa al texto sino algo que pasa por el texto, pues es menos cuestión de estructura y combinatorias que de competencia'. En este sentido, continúa, 'un género es ante todo una estrategia de comunicabilidad y es como marcas de esa comunicabilidad que un género se hace presente y analizable en el texto' (Subrayados en el original). Cf. Jesús Martín-Barbero, 'La telenovela en Colombia: Televisión, melodrama y vida cotidiana', en Nora Mazziotti (ed.), El espectáculo de la pasión. Las telenovelas latinoamericanas, Buenos Aires, Colihue, 1993, pp. 43-62, (p.56).

${ }^{13}$ Por la expresión 'operadores de sentido' entiendo aquí, siguiendo a Calabrese 'un núcleo motivador de la escritura, presente en cualquier campo del vasto archivo intertextual de la literatura y la cultura, así como al imaginario individual y/o social; en suma, es un disparador de la escritura que, por supuesto, permite atravesar los géneros aunque, por cierto, se vincule más estrechamente con el desarrollo de alguno de ellos. Tal es el caso del 'enigma' en relación con el género policial. Sin embargo, [...] esta noción excede los límites genéricos o, mejor dicho, no entra en colisión con los criterios taxonómicos'. Cf. Elisa Calabrese, 'Gestos del relato: El enigma, la observación la evocación', en Elsa Drucaroff (ed.), Historia crítica de la literatura argentina. La narración gana la partida, Buenos Aires, Emecé, 2000, pp. 73-96, (p.73).

${ }^{14}$ Cf. Ford, Navegaciones, p. 224.

15 Diversos estudios han demostrado que las personas prestan más atención y recuerdan con más precisión la información que los medios presentan de manera más personal, emocional o dramática, por cuanto tal forma narrativa ayudaría a producir un cierto grado de identificación entre el receptor del mensaje y la víctima de la noticia (para una revisión de estos estudios, ver Teun A. van Dijk, La noticia como discurso. Comprensión, estructura y producción de la información, Barcelona, Paidós, 1996.). En este sentido, muchas veces, 'casos testigos' que se desarrollan alrededor de la violencia ayudarían a conformar la opinión que los individuos se hacen acerca de la peligrosidad del mundo en el que viven, las conjeturas acerca de las posibilidades que tienen ellos mismos de ser víctimas de un posible crimen o delito, o la creación de un clima de desconfianza hacia los demás. Obviamente, todo esto contribuiría a deteriorar las redes sociales articuladas alrededor de la confianza interpersonal (cf. Virginia García Beaudoux y Orlando D’Adamo, 'Tratamiento del delito y la violencia en la prensa. Sus posibles efectos sobre la opinión pública', en Luchessi y Rodríguez, Fronteras Globales, pp. 169-185, [p. 179] y van Dijk, La noticia, p. 227). Por otra parte, no se puede olvidar, como señala Marcela Farré, que la percepción del mundo de una sociedad no es homogénea, y que se acepta, entre muchos posibles, un tipo de representación como el más adecuado. El predominio de algunos esquemas organizativos por sobre otros dependerá siempre de la legitimidad e incidencia que un grupo particular-social, cultural, económico, político- pudiera tener dentro de esa misma comunidad y de cómo utilizará ciertos mecanismos de refuerzos y recurrencias para difundirlos y reiterarlos en la sociedad (por ejemplo, a través de los medios o la educación). Sin duda, esto afectará la manera de representar la realidad, de verla y entenderla, poniendo en crisis, a su vez, el concepto de verdad (ver Néstor García Canclini, $L a$ globalización imaginada, México, Paidós, 1999, p.85 y Marcela Farré, El noticiero como mundo posible. Estrategias ficcionales en la información audiovisual, Buenos Aires, La Crujía, 2004, p.185).

${ }^{16}$ Para un seguimiento de estas muertes, ver Miguel Wiñazki, La noticia deseada. Leyendas y fantasmas de la opinión pública, Buenos Aires, Marea, 2004. 
${ }^{17}$ Para más detalles sobre el caso Yabrán, ver Hugo Hortiguera, 'News, Fiction and Marketing in a Time of Crisis. The Argentine Media and the Yabrán Case’, en Hortiguera y Rocha (eds), Argentinean Cultural Production, pp. 133-153.

${ }^{18}$ Ver Wiñazki, La noticia deseada, para seguir un interesantísimo recuento detallado de este caso. Por otro lado, Aníbal Ford ha señalado un problema epistemológico frecuente entre los conceptos de ficcionalización y narrativización. Una información -ya en el discurso oral o en el escrito- puede ser relatada siguiendo un procedimiento narrativo y esto es un recurso tan válido de seguir como la argumentación. Ahora bien, también se podrían transformar esos acontecimientos en algo que podría ser/haber sido inventado mediante un proceso de ficcionalización que apela a recursos teatrales, visuales, auditivos. Este fenómeno implica un 'contrato de lectura’ muy diferente con el público y se diferencia considerablemente de los contratos de la narración de la información o de la argumentación por su grado de espectacularización. (Ford, La marca, p. 249). Sobre esta base, entonces, en este trabajo distinguiré los conceptos de ‘ficcional' (y ‘ficcionalización’), de ‘ficticio’ y ‘factual'. Siguiendo a Farré, por ficcionalización (o por ficcional) entenderé -siempre con diversos grados- la representación de acciones reales, de sucesos del mundo real, mediante recursos prestados de la ficción artística (estrategias retóricas y estilísticas con las que se presenta la realidad y que pueden adoptar diversas formas, según sea en los niveles del enunciado, de la enunciación o en la situación comunicativa). Por ficticio, en tanto, designaré 'lo no existente' (acciones o personajes inexistentes o que nunca tuvieron lugar). Y con el tercer término aludiré a 'lo que es o ha tenido lugar'. Cf. Marcela Farré, El noticiero, pp. 193-207.

19 'Hay una política que se narra hoy en los diversos y cada vez más sorprendentes esguinces de la corrupción (más allá de los maniqueísmos fáciles) y una ficción que visibiliza en los medios una clase de relatos que penetran diariamente en la vida de la gente. Es evidente que la corrupción ya no solamente se identifica con el poder político sino que es una trama que involucra las más dispares áreas de la vida social: la economía, la tecnología, el deporte, los medios de comunicación y hasta la religión’ (Jesús Martín-Barbero y G. Rey, Los ejercicios del ver. Hegemonía audiovisual y ficción televisiva, Barcelona, Gedisa, 1999, p. 78). Como bien ejemplifican D’Adamo, García Beaudoux y Freidenberg, durante 2004 la cuestión de la inseguridad y el delito fue tema destacado de portada en el 86,5\% (45 semanas del año). Esto permitiría entender, prosiguen los autores, el permanente posicionamiento de este tema entre los tres de mayor preocupación para la gente. El efecto repetitivo proceso de cultivo mediante-, terminó inyectando en la población un efecto a largo plazo que se vio reflejado en sus valores, creencias e imágenes sobre la seguridad pública (Para más detalles ver Orlando D’Adamo, Virginia García Beaudoux y Flavia Freidenberg, Medios de comunicación y opinión pública, Madrid, McGraw Hill/Interamericana, 2007; García Beaudoux y D’Adamo, 'Tratamiento del delito'; y también Olga Wornat, Construcción imaginaria de la desigualdad social, Buenos Aires, CLACSO, Consejo Latinoamericano de Ciencias Sociales, 2007.). Así, recuérdense en ese sentido, como ejemplo, las protestas públicas de abril de ese mismo año, encabezadas por el pseudo ingeniero Juan Carlos Blumberg, a raíz del asesinato de su hijo Alex Blumberg en marzo de 2004. Las cuatro grandes manifestaciones que le siguieron al asesinato del joven tuvieron como objetivo reclamar penas más duras para una serie de delitos, limitaciones respecto del uso de las libertades bajo fianza y la reducción (a 14 años) de la edad de imputabilidad de los menores. Mientras tanto, en momentos en que esto se escribía -septiembre de 2008- el periódico porteño La Nación publicaba, en su sección de 'Información general' del domingo 28 de septiembre, tres notas en las que señalaba cómo la inseguridad pública se había adueñado de la sociedad y había cambiado significativamente las conductas de los ciudadanos en su vida cotidiana. Ver Loreley Gaffoglio, 'Nuevos hábitos: cómo la inseguridad transformó nuestra vida', La Nación 28 de setiembre de 2008, <http://www.lanacion.com.ar> y también 'Los cercos eléctricos, cada vez más comunes', La Nación 28 de setiembre de 2008, <http://www.lanacion.com.ar> y “"No nos queda otra que correr con el auto en la Panamericana." Crece el temor a abordajes en la autopista y al llegar al hogar', La Nación 28 de setiembre de 2008, <http://www.lanacion.com.ar>. Para una análisis de las discusiones sobre reformas policiales de este período y las consecuencias del caso Blumberg, ver Kent Eaton, 'Paradoxes of Police Reform. Federalism, Parties, and Civil Society in Argentina’s Public Security Crisis’. Latin American Research Review 43, 3, 2008, pp. 5-32. Para una excelente lectura del concepto de delito como ficción cultural que funda una cultura en un contexto de economía capitalista ver Josefina Ludmer, El cuerpo del delito. Un manual, Buenos Aires, Editorial Perfil, 1999.

${ }^{20}$ Lucrecia Escudero, 'El secreto como motor narrativo', en Eliseo Verón y Lucrecia Escudero (eds.), Telenovela, ficción popular y mutaciones culturales, Barcelona, Gedisa, 1997, pp.73-86. 
${ }^{21}$ Para mayores detalles sobre las influencias mutuas entre medios en la difusión de noticias, ver Lucrecia Escudero, 'La agenda de los medios', en Lucrecia Escudero y Claudia García Rubio (eds.), Democracias de opinión, pp. 130-175.

${ }^{22}$ Cf. Fernández Pedemonte, La violencia del relato. El fenómeno de la circularidad y desplazamiento de la información en la Argentina de los últimos años merecería un estudio mucho más extenso. Otro ejemplo notable se da en la relación entre los llamados realities y los 'programas de chimentos' (o cotilleos) que se emiten a toda hora. La Argentina no ha escapado al influjo de la televisión globalizada y programas como Gran hermano, Bailando..., Cantando... o Patinando con las estrellas (en Argentina aparecen con el nombre Bailando..., Cantando... o Patinando por un sueño) y otros similares han inundado sus pantallas. Lo interesante en estos programas es ver cómo el tema central del reality -el baile, el canto o el patinaje- ha sido desvirtuado, para terminar enfocándose alrededor del conflicto mediático que se establece siempre entre los participantes, los participantes y los jueces o los jueces entre sí (en donde, muchas veces, aflora la idea de 'complot' en contra de un participante o juez). Sistemáticamente, las peleas y escándalos -muchos de ellos armados- son retomados, repetidos y continuados en los innumerables programas de chimentos en los días sucesivos, no sólo de la misma estación de televisión sino de otros de la competencia. En muchas oportunidades, estas 'historias' estallan, para desplazarse de un medio a otro, abriendo otros micro-relatos que saltan a la radio o encuentran su lugar en revistas del corazón y hasta en la sección de espectáculo de los periódicos. Interminables horas de emisión y largo centimetraje son dedicados todos los días a difundir estas extrañas 'seudo-noticias' en todos los medios (cf. Alicia Entel, 'Historiadores del presente', en Alicia Entel (ed.), Periodistas: entre el protagonismo y el riesgo, Buenos Aires, Paidós, 1997, pp.11-25, [p. 17]). Para un lector interesado en los conceptos de 'escándalo mediático', que excede los límites de este trabajo, remito a los estudios de James Lull y Stephen Hinerman (eds), Media Scandals, Cambridge, Polity Press, 1997; John Thompson, Political Scandal: Power and Visibility in the Media Age, Cambridge, Polito Press, 2000; y Howard Tumber y Silvio Waisbord, 'Introduction: Political Scandals and Media Across Democracias, Volume 1', American Behavioral Scientist 47, 8, 2004, pp.1031- 1039 .

${ }^{23}$ Según el periodista Dardo Fernández, director del sitio online Diario sobre Diarios, el fenómeno de ausencia de fuentes o 'fuente anónima' se habría iniciado en los '90 y agudizado durante el gobierno de Néstor Kirchner. De acuerdo con Fernández, la prensa acudiría a esa práctica toda vez que la noticia tuviera su origen en el gobierno (para más detalles, ver Jorge Halperín, Noticias del poder. Buenas y malas artes del periodismo político, Buenos Aires, Aguilar, 2007, pp. 75 y ss). El 'contrato de lectura' ha sido definido por Eliseo Verón como la 'construcción de un lazo que une en el tiempo un medio y sus consumidores’ y cuyo objetivo es ‘construir y preservar los hábitos de consumo’ (Verón, citado por Ivana Romero, 'Pequeño Verón ilustrado: Podría ser más grosero’ (entrevista a Eliseo Verón), El ciudadano \& la región, 15 de julio de 2004 (10 agosto de 2006), <http://archivoelciudadano.com.ar/15-07-2004/cultura/grosero.php\#>). Por su parte, Lucrecia Escudero lo define como una 'forma particular de contrato fiduciario que trata de establecer con sus lectores el medio por el cual éstos aceptan ‘a priori’ como verdadera la narración vehiculizada reservándose ‘a posteriori’ la posibilidad de verificación, otorgándole al medio una legitimidad fundada en la institución que representa' (Lucrecia Escudero, Malvinas: El gran relato. Fuentes y rumores en la información de guerra, Barcelona, Gedisa, 1996, p.47).

${ }^{24}$ Por cuestiones de espacio, resulta imposible aquí extenderse en detalles de estos casos. Para un lector interesado en el caso Yabrán y sus relaciones con la telenovela Ricos y famosos (1996), de Hugo Moser, emitida en Canal 9 de Buenos Aires ver Hortiguera, 'News, Fiction and Marketing'. En lo que se refiere al caso de la corrupción en el senado, el seguimiento de la prensa durante los meses de junio y agosto de 2000, y las consecuencias mediáticas y políticas del caso, ver Hugo Hortiguera, 'Seduciendo desde la frontera: folletín, pasión y suspenso en el periodismo argentino del nuevo milenio', Antípodas. Journal of Hispanic and Galician Studies 16, 2005, pp. 131-144. Para una descripción del asalto a la oficina bancaria del Banco Río, en la provincia de Buenos Aires, el 13 de enero de 2006, y su cobertura periodística, ver 'Así elogió la prensa argentina a los ladrones que robaron una sucursal del Banco Río’, Diario sobre Diarios, 26 de enero de 2006 (10 de enero de 2007), <http://www.diariosobrediarios.com.ar/dsd/diarios/zona_dura/26-01-2006.htm>. Sobre el tratamiento que dio la prensa al asesinato de María Marta García Belsunce, el 27 de octubre de 2002, ver el trabajo de Hugo Hortiguera, 'Productos mediáticos: El affair Belsunce y el suspenso permanente de la realidad', Estudios sobre el mensaje periodístico 11, Universidad Complutense de Madrid, 2005, pp.53-64. Finalmente, para detalles sobre el asesinato de Nora Dalmasso y las aristas sensacionalistas que le dieron los medios al caso ver 'Río Cuarto: la construcción de un "juego sexual” como causa de muerte que no se pudo comprobar. La "hipoxifilia" difundida por los medios y 
desmentida por la Justicia', Diario sobre diarios, 12 de diciembre de 2006, (10 de enero de 2007), $<$ http://www.diariosobrediarios.com.ar/dsd/diarios/zona_dura/12-12-2006.htm>.

${ }^{25}$ Por 'estética fuzzy' (concepto tomado de Vilches) se entiende aquí una aproximación estetizante que trasciende los opuestos y absolutos. En la práctica, esto significaría una disolución e interpenetrabilidad de géneros que conlleva la creación de un espacio ambivalente, marcado por lo impreciso, difuso e inestable, inacabable y sostenido en el tiempo, carente de clausura y siempre cruzado por lo irracional y conflictivo. Para mayores detalles sobre este concepto, cf. Lorenzo Vilches, La migración digital, Barcelona, Gedisa, 2001. Un ejemplo notable es el tratamiento que los noticiarios de los canales de aire comienzan a hacer con ciertas noticias en este período. En este sentido, el noticiero de Canal 13 (también del grupo Clarín) fue quizás uno de los pioneros, cuando, en 1998, hablando de la crisis económica, incluyó una encuesta callejera a supuestos 'ciudadanos comunes', entre los que se insertaban testimonios de los personajes -no de los actores- de la telenovela Gasoleros, proyectada por ese entonces en el mismo canal. (Es significativo que esta práctica se hubiera desarrollado paralelamente en dos medios pertenecientes al mismo conglomerado: el periódico Clarín y su estación televisiva). Un proceso similar se reiteró un año más tarde en el mismo informativo, con la telenovela Campeones de la vida (Canal 13, 1999), protagonizada por el actor Osvaldo Laport, quien encarnaba en la ficción a un boxeador. Cada encuentro boxístico del personaje de Laport en la telenovela de rigor era anunciado, comentado y analizado en el informativo del canal como si se tratara de un encuentro pugilístico real. Pero los juegos también se extendieron a una especial puesta en escena de las noticias televisivas, en las que se llegaron a incluir recursos técnicos-visuales (teatralizaciones o recreaciones), semántico-narrativos (uso de diversos planos, difuminaciones, cámaras lentas, repeticiones, flashbacks o raccontos, etc.), lingüísticos (predominancia de un uso poético del lenguaje), y sonoros (musicalización dramática de las notas), dispositivos todos más cercanos a un universo ficcional que a uno informativo (para un detallado análisis de todos estos conceptos y prácticas en los medios argentinos, véase Farré, El noticiero como mundo posible y Mario Carlón, Sobre lo televisivo. Dispositivos, discursos y sujetos, Buenos Aires, La Crujía, 2004.).

${ }^{26}$ Hortiguera, 'Productos mediáticos'.

${ }^{27}$ Cristian Alarcón, 'Lo único real que tenemos es un cadáver' (Entrevista a Vicente Battista). Página/12 12 de julio de 2007 (13 de julio de 2007), <http://www.pagina12.com.ar>. Algo similar ocurrirá también con la muerte del empresario Yabrán y el artículo que el escritor Guillermo Saccomanno escribiera en Página 12 sobre los últimos momentos de Alfredo Yabrán, cruzando formas típicas del policial con el recuento documental. Para más detalles, ver Hortiguera, 'News, Fiction and Marketing'.

${ }^{28}$ Walter Slavich, 'Asalto en Acassuso: La realidad transformada en ficción: Un guión de TV para el robo al banco', Clarín 16 de enero de 2001, (10 de marzo de 2007), <http://www.clarin.com.ar>.

${ }^{29}$ Volanta (o 'bajada') del diario a la nota de Claudia Piñeiro, 'Zona de autor: Ganas de matar', Clarín, Suplemento Zona, 24 de febrero de 2008 (20 de marzo de 2008), <www.clarin.com.ar>.

${ }^{30}$ No puedo dejar de mencionar la oportunista publicación de esta novela, que aprovechaba la curiosidad morbosa sobre la vida cotidiana en los countries que el caso Belsunce había despertado entre la población.

31 'En el contrato de información predomina el (...) propósito (...) de "hacer saber”, que se relaciona con la verdad, que supone que el mundo existe por sí mismo y que puede informarse acerca de él con seriedad en una escena de significación considerada "real". La segunda finalidad, la de "hacer sentir", sería secundaria en un contrato de este tipo pues, como se relaciona con la seducción, permite suponer, a la inversa del propósito anterior, que el mundo sólo es apariencia y que, por consiguiente, sólo puede informarse acerca de él por "placer" en un escenario de significación considerado 'ficcional”" (Patrick Chareaudeau, El discurso de la información. La construcción del espejo social, Barcelona, Gedisa, 2003, p. 86).

${ }^{32}$ Cf. Ford, La marca y Martín-Barbero y Rey, Los ejercicios del ver.

${ }^{33}$ El caso de Mujeres asesinas (2000) es interesante de mencionar aquí. Cuatro años más tarde de su publicación, Pol-ka, productora de televisión asociada a Canal 13 (del grupo Clarín), compró los derechos de adaptación para producir una serie semanal. El programa, cuyos guiones para la televisión fueron escritos por la misma Marisa Grinstein, y por Liliana Escliar, Walter Slavich y Marcelo Slavich, no causó gran impacto en sus primeros capítulos. Sin embargo, pronto se convirtió en programa de culto, llegando a emitirse setenta y ocho capítulos, a lo largo de cuatro temporadas (desde 2004 a 2008). Con elementos (melo)dramáticos, la serie escenificaba cada semana, como en la antología en la que se había inspirado, un caso criminal real perpetrado por mujeres. El éxito hizo que productoras de otros países se interesaran por él y el formato fuera vendido a la televisión colombiana y mexicana, en donde comenzó a proyectarse en 2007 y 2008 respectivamente. Pero también permitió que el libro 
original se reeditara unos años más tarde en Buenos Aires y, gracias a las emisiones televisivas y a la difusión que el thriller folletinesco tenía en la sociedad, se convirtiera en un best-seller y se publicara un par de secuelas con nuevos casos.

${ }^{34}$ Henry Jenkins ha observado que en el contexto global 'muchos de los grandes gigantes mediáticos parecen grandes familias disfuncionales, cuyos miembros no se hablan y siguen sus propias agendas a corto plazo, incluso a expensas de otras divisiones de las mismas compañías'. A contrapelo de esta aserción, lo particular del caso argentino parece radicar en esta curiosa apelación a este género en particular como elemento unificador para lograr una coordinación y articulación entre las distintas plataformas mediáticas que estas empresas poseen. Cf. Henry Jenkins, Convergence Culture. La cultura de la convergencia de los medios de comunicación, Barcelona, Paidós, 2008, p.19.

35 Jenkins, Convergence Culture, p. 29.

${ }^{36}$ Ver Oscar Steimberg, Semiótica de los medios masivos. El pasaje de los medios a los géneros populares, Buenos Aires, Atuel, 1998.

37 Ver John Saxe-Fernández, 'Globalización e imperalismo', en John Saxe-Fernández (ed.), Globalización: crítica a un paradigma, México, UNAM-Plaza y Janés, 1999, pp.9-68 y Atilio Borón, 'La sociedad civil después del diluvio neoliberal', en Emir Sader y Pablo Gentili (eds.), La trama del neoliberalismo: mercado, crisis y exclusión social, Buenos Aires, CLACSO-Eudeba, 1999, pp. $43-87$.

38 Sergio Caletti, 'La política que está (representada) en otra parte', en Entel, Periodistas, 73-107, (p. 95). De hecho, esta práctica no pasó inadvertida para algunos intelectuales argentinos. Así, ya el 28 de marzo de 2004, escritores como José Pablo Feinmann, Juan Martini, Guillermo Piro o Sergio Sinay, reflexionaban sobre algunos de estos rasgos en una larga nota de la periodista Astrid Pikielny para el suplemento Enfoques del diario La Nación. Como bien señalaba Feinmann por entonces, 'la concentración de los medios de comunicación en pocas manos [era] un factor insoslayable a la hora de analizar cómo se escrib[ía] esta novela policial por entregas' que impregnaba los medios con sus historias inconclusas sobre crímenes, delitos y enigmas. Cf. Astrid Pikielny, 'Los diarios y la realidad: la novela argentina’, La Nación, Suplemento Enfoques, 28 de marzo de 2004 (10 de mayo de 2004), $<$ www.lanacion.com.ar>. 